\title{
VARIAÇÃO SAZONAL DA FOTOSSÍNTESE, CONDUTÂNCIA ESTOMÁTICA E POTENCIAL DA ÁGUA NA FOLHA DE LARANJEIRA 'VALÊNCIA'
}

\author{
Eduardo Caruso Machado ${ }^{1,4 *}$; Camilo Lázaro Medina ${ }^{2,5}$; Mara de Menezes de Assis Gomes ${ }^{2,6}$; \\ Gustavo Habermann ${ }^{3,5}$ \\ Centro de Ecofisiologia e Biofísica - IAC, C.P. 28 - CEP: 13001-970 - Campinas, SP. \\ ${ }^{2}$ Pós-Graduando em Biologia Vegetal - UNICAMP/Instituto de Biologia, C.P. 6109 - CEP: 13083-970 - \\ Campinas - SP. \\ ${ }^{3}$ Pós-Graduando em Botânica - UNESP/Instituto de Biociências, C.P. 510 - CEP: 18618-000 - \\ Botucatu - SP. \\ ${ }^{4}$ Bolsista CNPq. \\ ${ }^{5}$ Bolsista FAPESP. \\ ${ }^{6}$ Bolsista CAPES. \\ *Autor correspondente <caruso@barao.iac.br>
}

RESUMO: Em espécies perenes podem ocorrer variações nas taxas de trocas gasosas e nas relações hídricas em função da variação das condições ambientais, durante os diferentes meses do ano. Avaliaram-se, em laranjeira 'Valência' enxertada sobre quatro espécies de porta-enxerto, mantida sem deficiência hídrica, as taxas de fotossíntese $(\boldsymbol{A})$ e de transpiração $(\boldsymbol{E})$, a condutância estomática $(\boldsymbol{g})$ e o potencial da água na folha $\left(\Psi_{f}\right)$, medidos nos períodos da manhã $(9 \mathrm{~h} 00$ às $11 \mathrm{~h} 00)$ e da tarde $(13 \mathrm{~h} 00$ às $15 \mathrm{~h} 00)$ nos meses de janeiro, março e julho em Campinas - SP. As espécies de porta-enxertos não tiveram efeitos sobre as variáveis medidas. Independente do porta-enxerto $\boldsymbol{A}, \boldsymbol{g}$ e $\boldsymbol{\Psi}_{f}$ foram menores no período da tarde. A queda de $\boldsymbol{A}$ deve estar relacionada com a queda de $\boldsymbol{g}$ que diminuiu em resposta ao aumento do déficit de pressão de vapor entre o ar e a folha ( $\left.\boldsymbol{D P} \boldsymbol{V}_{\text {ar-fol ha }}\right)$ nos horários mais quentes do dia. Apesar de ocorrer fechamento parcial dos

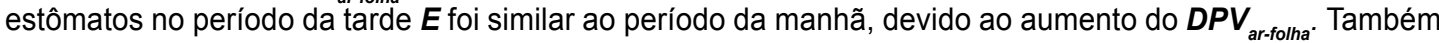
observou-se queda em $\boldsymbol{A}$ e em $\boldsymbol{g}$ no sentido de janeiro para julho. Sugere-se que a queda em $\boldsymbol{A}$ e em $\boldsymbol{g}$ ocorrida em março em comparação a janeiro esteja relacionada à queda da atividade de crescimento da planta, afetando as relações fonte-dreno, visto que as condições ambientais nestes dois meses foram semelhantes. As quedas de $\boldsymbol{A}$ e de $\boldsymbol{g}$ observadas em julho, em relação à janeiro e março, parecem estar relacionadas tanto à queda na temperatura noturna quanto à queda na atividade de crescimento.

Palavras-chave: Citrus sinensis, trocas gasosas, transpiração, crescimento

\section{SEASONAL VARIATION OF PHOTOSYNTHETIC RATES, STOMATAL CONDUCTANCE AND LEAF WATER POTENTIAL IN 'VALENCIA' ORANGE TREES}

\begin{abstract}
Seasonal variation in environmental conditions may influence gas exchange rates as well as water relations in perennial species. This work was carried out to evaluate photosynthetic rates $(\boldsymbol{A})$, transpiration $(E)$, stomatal conductance $(g)$ and leaf water potential $\left(\Psi_{f}\right)$ in 'Valencia' orange trees grafted on four different rootstocks. Measurements were made twice a day: from 9 h00 to $11 \mathrm{~h} 00$ a.m. and from 1 h00 to 3h00 p.m., during January, March and July. $\boldsymbol{A}$ and $\boldsymbol{g}$ were significantly lower and $\boldsymbol{\Psi}_{\boldsymbol{f}}$ was significantly more negative, in the afternoon. The decrease in $\boldsymbol{A}$ may be related to the reduction in $\boldsymbol{g}$, due to the increase in the vapor pressure deficit between the air and the leaf $\left(\boldsymbol{V P D _ { \text { air-leaf } }}\right)$ in the afternoon, when temperatures are higher. In spite of the partial stomatal closure in the afternoon, the values for $\boldsymbol{E}$ were approximately the same as those measured in the morning, due to the increase in the $\boldsymbol{V P \boldsymbol { D } _ { \text { air-leaf } }}$. A decrease in $\boldsymbol{A}$ and $\boldsymbol{g}$ could also be noted from January to July, that is, from the hot and humid summer months, to the colder and drier winter ones. It was suggested that the decrease in $\boldsymbol{A}$ and $\boldsymbol{g}$ observed from January through March, may be related to the decrease in plant growth rates, which could have influenced the source-sink relationships, since the climatic conditions for both months were similar. The decrease in $\boldsymbol{A}$ and $\boldsymbol{g}$ showed in July, seems to be related to the decrease in both the night temperature and the growth rate of plants.

Key words: Citrus sinensis, growth, gas exchange, transpiration
\end{abstract}

\section{INTRODUÇÃO}

O clima no Estado de São Paulo caracteriza-se por um verão úmido, com níveis de energia solar típico do trópico e um período de inverno seco com temperaturas amenas e precipitação pluviométrica reduzida. De julho a agosto, existem condições térmicas e hídricas que condicionam o repouso vegetativo e em setembro condições favoráveis para o florescimento em laranjeiras. Na primavera, após a antese, nas fases 
iniciais de crescimento do fruto e da área foliar, o nível de radiação solar é mais elevado, os dias são mais longos, as temperaturas mais altas e, geralmente, há boa disponibilidade de água. O crescimento dos frutos depende do suprimento de substrato fotossintetizado sendo, portanto, favorecidos por condições adequadas a altas taxas de fotossíntese.

A taxa máxima de fotossíntese de Citrus sinensis (L.) Osbeck ocorre em temperaturas do ar em torno de $22^{\circ} \mathrm{C}$ a $25^{\circ} \mathrm{C}$ (Kriedmann, 1971; Khairi \& Hall, 1976). Sob condições naturais, sem deficiência hídrica no solo e com fluxo fotossintético de fótons saturante, a taxa de fotossíntese é máxima ao redor das $9 \mathrm{~h} 30$, decrescendo posteriormente, com o aumento da temperatura e do déficit de pressão de vapor (DPV) (Habermann, 1999; Medina et al., 1999). A redução na taxa de fotossíntese com o aumento de DPV e da temperatura está relacionada, respectivamente, com a queda da condutância total da folha e da condutância do mesofilo (Khairi \& Hall, 1976; Machado et al., 1994; Medina et al., 1998, 1999). A taxa de transpiração em citros aumenta com o DPV, apesar dos estômatos se fecharem parcialmente, consequentemente a eficiência instantânea do uso da água pela planta é menor nos horários de alta demanda atmosférica por água (Brakke \& Allen Jr., 1995; Medina et al., 1999). Também em outras espécies arbóreas observaram-se menores taxas de fotossíntese no período da tarde, parecendo estarem relacionadas com o valor do DPV no ar e com o DPV entre o ar e a folha (Eamus \& Cole, 1997; Prior et al., 1997).

A variação sazonal da taxa de fotossíntese e da condutância do estômatos em espécies arbóreas, nas regiões tropicais, está relacionada com as condições de DPV, temperatura do ar e principalmente umidade do solo, característica de cada estação do ano (Eamus \& Cole, 1997; Prior et al., 1997). A queda da taxa de fotossíntese em laranjeiras em função da queda no teor de umidade no solo foi relatada por vários autores (Syvertsen \& Lloyd, 1994; Medina et al., 1998, 1999).

Nas condições do Estado de São Paulo observam-se, em laranjeiras, que fluxos característicos de crescimento vegetativo ocorrem em função das estações do ano, que possivelmente estão relacionados com variações na taxa de fotossíntese. No entanto não há referências a estudos sobre fotossíntese em diferentes meses do ano.

Comercialmente as laranjeiras são propagadas, principalmente, por enxertia, sendo que existem várias combinações de porta-enxertos e copas. Os portaenxertos afetam inúmeras características como tolerância a seca, a taxa de fotossíntese, susceptibilidade a doenças e outras (Pompeu Jr., 1991). As diversas combinações porta-enxerto e copas podem induzir diferentes respostas em relação às condições ambientais características de cada época do ano.

Este trabalho teve como objetivo determinar as respostas da fotossíntese, da condutância estomática, da transpiração e do potencial da água na folha às condições ambientais nos meses de janeiro, março e julho, em laranjeira 'Valência' sobre quatro espécies de porta-enxertos, sem deficiência hídrica.

\section{MATERIAL E MÉTODOS}

\section{Local do experimento}

O experimento foi instalado sob telado do Centro de Ecofisiologia e Biofísica no Núcleo Experimental de Campinas do Instituto Agronômico, Campinas - SP. Utilizou-se vinte e quatro plantas de laranjeira 'Valência', de aproximadamente três anos, seis enxertadas sobre cada um dos seguintes porta-enxertos: limoeiro 'Cravo', 'Trifoliata', tangerina 'Cleópatra' e citrange 'Troyer'. 'Valência' é um dos principais cultivares utilizados na citricultura paulista. São plantas vigorosas e produtivas com ampla adaptabilidade às diferentes regiões de cultivo (Figueiredo, 1991). O limoeiro 'Cravo' é o principal porta-enxerto da citricultura brasileira constituindo mais de $90 \%$ dos pomares. A tangerina 'Cleópatra' tem sido uma alternativa ao limoeiro 'Cravo' por induzir maior tolerância ao declínio bem como induzir boa qualidade dos frutos. O 'Trifoliata' é um porta-enxerto que induz um menor desenvolvimento das plantas, permitindo maior adensamento de plantio. $O$ citrange 'Troyer' não tem uma utilização expressiva na citricultura brasileira, mas induz boa tolerância a Phytophthora e favorece a qualidade de frutos (Pompeu Jr., 1991).

Aproximadamente um ano antes do início do experimento, estas plantas foram transplantadas para seis tanques; cada um deles com quatro plantas, uma por porta-enxerto. Cada tanque possui $4,0 \mathrm{~m}$ de comprimento por $0,5 \mathrm{~m}$ de largura por $0,6 \mathrm{~m}$ de profundidade e esta repleto de terra fértil. Os tanques com as plantas foram irrigados mantendo-se a terra com umidade próxima à capacidade de campo.

Os dados climáticos foram coletados no Posto Meteorológico do Núcleo Experimental de Campinas, localizado a aproximadamente $500 \mathrm{~m}$ do telado onde foi instalado o experimento.

As medidas descritas abaixo foram coletadas em dias claros nos meses de janeiro (21 e 22), março (10 e 11) e julho (7 e 8) de 1998.

\section{Potencial da água na folha}

O potencial da água nas folhas $\left(\Psi_{f}\right)$ foi determinado pelo método descrito por Kaufmann (1968) com uma câmara de pressão (PMS mod. 1002), às 7 h00 e às $14 \mathrm{~h} 00$, com três repetições para cada tratamento. As folhas utilizadas foram as localizadas do lado oposto àquelas utilizadas nas medidas de trocas gasosas.

\section{Medidas de trocas gasosas}

As taxa de fotossíntese $(\boldsymbol{A})$ e de transpiração $(E)$ e a condutância estomática $(\boldsymbol{g})$ foram medidas por meio do método descrito em Medina et al. (1998), utilizando um aparelho portátil de fotossíntese (Li-6200, Licor Ltda., 
Lincoln, NE). As medidas de trocas gasosas foram feitas no período da manhã, entre $9 \mathrm{~h} 00$ e $11 \mathrm{~h} 00$, e no período da tarde, entre $13 \mathrm{~h} 00$ e $15 \mathrm{~h} 00$. Somente foram considerados os dados medidos quando o fluxo fotossintético de fotóns (FFF) era maior que 700 $\mu \mathrm{mol} \mathrm{m} \mathrm{m}^{-2} \mathrm{~s}^{-1}$, isto é, quando em níveis saturantes para a fotossíntese em citros (Kriedmann, 1971; Habermann, 1999). As folhas utilizadas nas diferentes épocas de medidas tinham idade aproximadamente iguais, isto é, ao redor de seis meses. Também foram medidas as temperaturas de bulbo úmido e seco, com um psicrômetro com termômetros de mercúrio, e calculados os déficits de pressão de saturação de vapor no $\operatorname{ar}\left(D P V_{\text {ar }}\right)$ e entre o ar e a folha ( $\left.\boldsymbol{D} \boldsymbol{P \boldsymbol { V } _ { \text { ar-folha } }}\right)$.

$\mathrm{O}$ delineamento experimental foi em blocos ao acaso com seis repetições. Médias e desvio padrão foram calculados para os dados mensais e diários. As comparações de $\boldsymbol{A}, \boldsymbol{g}, \boldsymbol{E}$ e de $\boldsymbol{\Psi}_{\mathrm{f}}$ entre período da manhã e da tarde e entre meses foram feitas por meio de análise de variância. Onde o fator era significativo a $5 \%$, as médias foram comparadas por meio do teste de Tukey a $5 \%$.

\section{RESULTADOS E DISCUSSÃO}

\section{Clima}

A temperatura do ar, radiação solar global incidente e o $D P V_{a r}$ nos respectivos dias de medidas das trocas gasosas são apresentados na Figura 1. Em janeiro e março as temperaturas instantâneas variaram entre $20^{\circ} \mathrm{C}$ e $34^{\circ} \mathrm{C}$ e em julho entre $13^{\circ} \mathrm{C}$ e $26^{\circ} \mathrm{C}$, portanto, as máximas e mínimas em janeiro e março foram , respectivamente, $8^{\circ} \mathrm{C}$ e $7^{\circ} \mathrm{C}$ superiores às observadas em julho. A radiação solar incidente foi similar em janeiro e março, porém superior à de julho (Figura 1). Em todos meses estudados os valores instantâneos máximos do $D P V_{\text {ar }}$ ocorreram nas horas com temperaturas mais elevadas, em geral ao redor das $13 \mathrm{~h} 00$, e os mínimos pouco antes do amanhecer. Os maiores valores de $D P V_{\text {ar }}$ foram observados nos meses de janeiro e março no período da tarde.

\section{Efeito do período do dia sobre as taxas de fotossíntese e transpiração, condutância estomática e potencial da água na folha}

As trocas gasosas (taxa de fotossíntese, transpiração e condutância estomática) em laranjeiras 'Valência' sobre os diferentes porta-enxertos foram estatísticamente semelhantes (análise não apresentada), conforme também foi relatado por Medina et al. (1998) (Figura 2). Desta forma, as análises comparativas das respostas das variáveis medidas nos diferentes períodos do dia e meses serão feitas em conjunto, não considerando-se os porta-enxertos individualmente.

Em janeiro e março, a taxa de fotossíntese no período da manhã, entre $9 \mathrm{~h} 00$ e $11 \mathrm{~h} 00$, foi maior que no período da tarde, entre $13 \mathrm{~h} 00$ e $15 \mathrm{~h} 00$ horas e aproximadamente iguais em ambos períodos no mês de
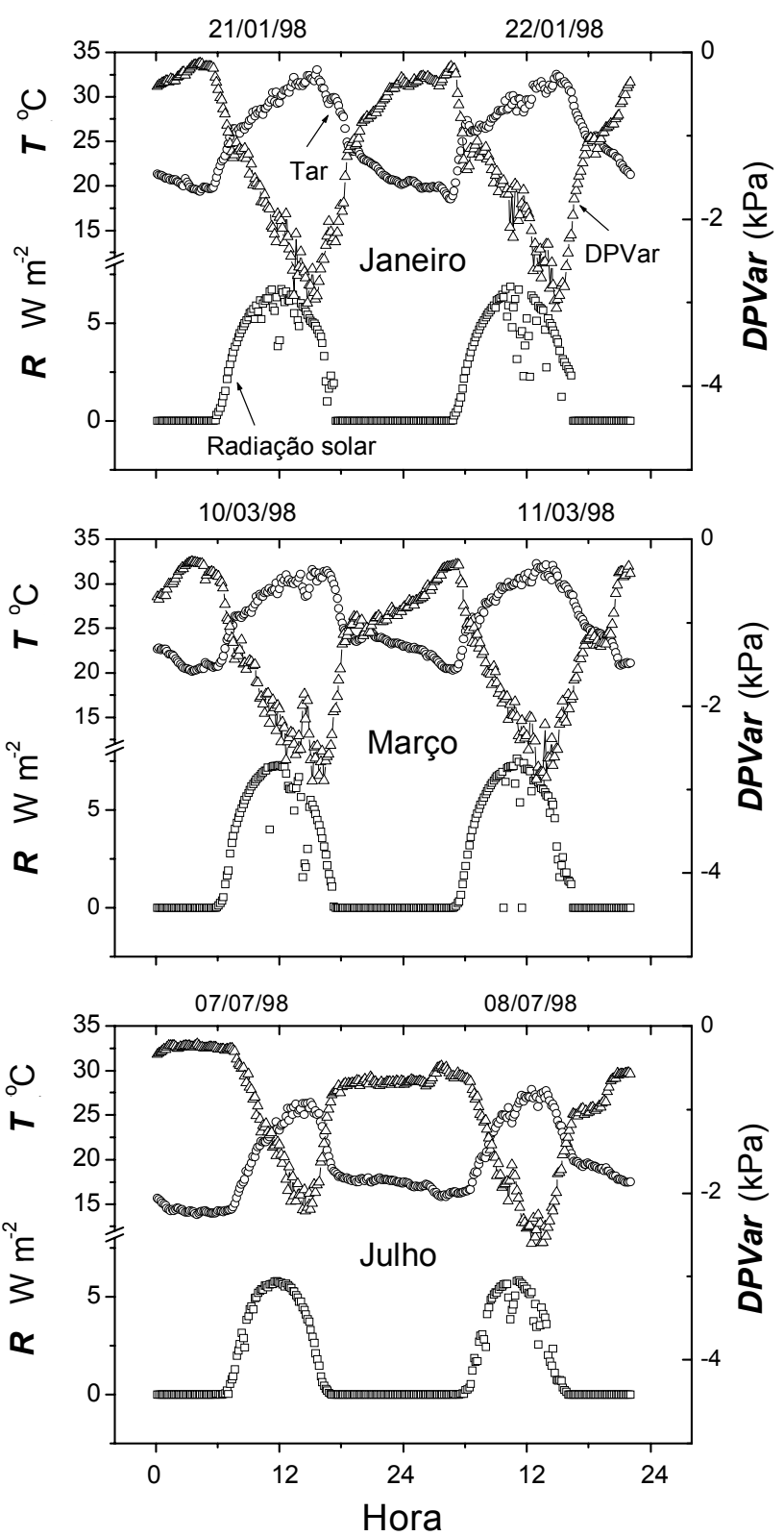

Figura 1 - Variação da temperatura do $\operatorname{ar}(T)$, da radiação solar $(R)$ e do déficit de pressão de vapor do ar $\left(D P V_{a r}\right)$ nos dias de medidas de trocas gasosas em laranjeira 'Valência' sobre quatro espécies de porta-enxerto. Campinas, 1998.

julho. A diferença entre a fotossíntese média, nos dois períodos, foi menor em março que em janeiro e praticamente inexistente no mês de julho. Medina et al. (1999), em medidas efetuadas em janeiro também observaram taxas de fotossíntese mais altas no período da manhã. $O$ mesmo foi relatado para outras espécies arbóreas (Eamus \& Cole, 1997; Prior et al., 1997).

A condutância estomática apresentou padrões similares ao da fotossíntese, sugerindo que a queda da taxa de fotossíntese esteja relacionada com o fechamento parcial dos estômatos (Figura 2). Nos três meses, as taxas de transpiração nos dois períodos foram similares, apesar de no período da tarde ter 
ocorrido queda na condutância estomática, exceto em julho. A semelhança da transpiração nos dois períodos deve-se ao efeito dos maiores valores de $D P V_{a r}$ e/ou do $D P V_{\text {ar-folha }}$ no período da tarde, isto é, uma demanda atmosférica maior (Figuras 1 e 3). Devido a fotossíntese diminuir à tarde, mas não a transpiração, a eficiência do uso da água, expressa pela razão $A / E$, foi menor no período da tarde, sobretudo em janeiro e março (Figura 4).

A condutância estomática apresentou valores maiores na parte da manhã (Figura 2), porém a relação $\boldsymbol{A} \mathbf{g}$ permaneceu praticamente inalterada nos dois períodos em janeiro (Figura 5), sugerindo que ambos processos foram afetados com intensidade similar no decorrer de um dia. No entanto, a relação $\boldsymbol{A} / \boldsymbol{g}$ à tarde foi progressivamente maior em março e em julho, indicando que a fotossíntese foi relativamente menos afetada que a abertura estomática. Assim, em março e em julho para qualquer valor de condutância estomática a fotossíntese é menor na parte da manhã (Figura 5), possivelmente devido ao efeito relativamente maior do $D P V_{\text {ar-folha }}$ e da temperatura sobre a condutância estomática. Em função da maior razão $\boldsymbol{A} / \boldsymbol{g}$ no período da tarde, em março e julho, a concentração interna de $\mathrm{CO}_{2}$ também foi menor neste período (Tabela 1).

Como as medidas de fotossíntese consideradas (entre 9 e $11 \mathrm{~h} 00$ e entre 13 e $15 \mathrm{~h} 00$ ) foram somente aquelas em que o FFF era maior que $700 \mu \mathrm{mol} \mathrm{m} \mathrm{m}^{-2} \mathrm{~s}^{-1}$, ou seja em intensidade próxima à saturação da fotossíntese, as diferenças observadas nos dois períodos possivelmente não estão relacionadas com este fator. Algumas espécies podem apresentar queda na taxa de fotossíntese por fotooxidação devida à radiação solar excessiva (Kitao et al., 2000), porém tal fenômeno não foi ainda relatado para laranjeira.

A queda da fotossíntese a tarde em janeiro e março pode estar relacionada com a variação da temperatura e conseqüente variação de $D P V_{a r}$ e $D P V_{a r}$ folha. Khairi \& Hall (1976) e Hall et al. (1975) observaram efeitos significativos da temperatura sobre a condutância e fotossíntese em citros. No entanto, é importante

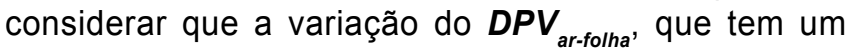
efeito significante sobre a condutância é, principalmente, função da temperatura da folha. Em citros, a condutância estomática máxima ocorre ao redor de $30^{\circ} \mathrm{C}$, enquanto que fotossíntese máxima ocorre entre $22^{\circ} \mathrm{C}$ e $25^{\circ} \mathrm{C}$ (Kriedmann, 1971; Hall et al., 1975; Khairi \& Hall, 1976; Habermann, 1999). A redução na taxa de fotossíntese com o aumento do $\boldsymbol{D P V _ { \text { ar } }}$ e da temperatura está relacionada, respectivamente, com a queda da condutância total da folha e da condutância do mesófilo (Khairi \& Hall, 1976; Machado et al., 1994; Medina et al., 1998, 1999). Presume-se que este tipo de resposta dos estômatos, em citros e em outras espécies, ao aumento do $D P V_{\text {ar-folha }}$ e da temperatura seja uma adaptação evolutiva para conservar água, principalmente em regiões onde há alta demanda atmosférica. Assim, em

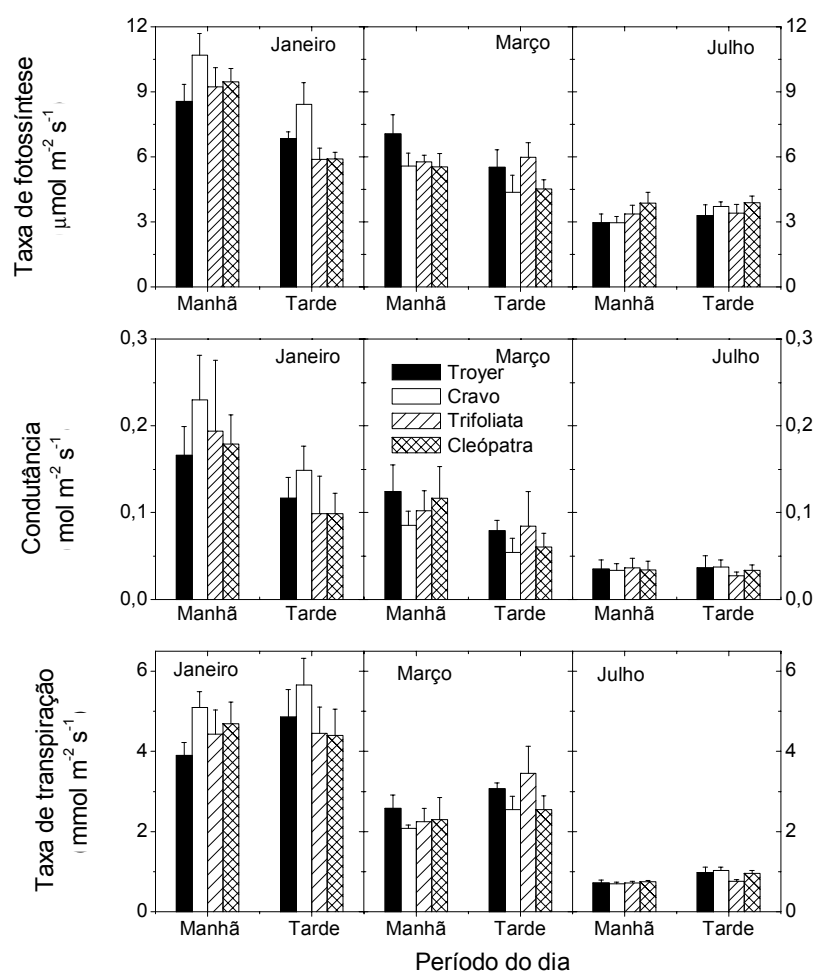

Figura 2 - Variação da taxa de fotossíntese, da condutância estomática e da transpiração em função do período do dia e do mês de medida em laranjeira 'Valência' sobre quatro espécies de porta-enxerto. Barras indicam desvio padrão da média. Campinas, 1998.

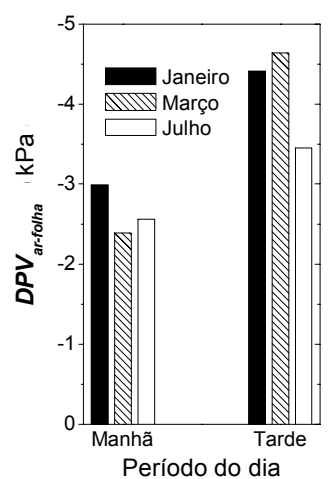

Figura 3 - Variação do déficit de pressão de vapor entre o ar e a folha $\left(D P V_{\text {ar-folha }}\right)$ em função do período do dia e do mês de medida em laranjeira 'Valência' sobre quatro espécies de porta-enxerto. Campinas, 1998.

Tabela 1 - Concentração interna de $\mathrm{CO}_{2}$ na câmara subestomática em laranjeira 'Valência' em diferentes meses do ano, no período da manhã e da tarde. Campinas, 1998.

\begin{tabular}{|c|c|c|}
\hline \multirow[t]{2}{*}{ MÊS } & \multicolumn{2}{|c|}{ PERÍODO } \\
\hline & MANHÃ & TARDE \\
\hline & \multicolumn{2}{|c|}{ 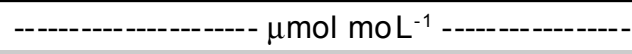 } \\
\hline JANE IRO & $237,1^{\mathrm{A}}$ & $241,1^{A}$ \\
\hline MARÇO & $248,9^{A}$ & $186,2^{c}$ \\
\hline JULHO & $219,7^{\mathrm{B}}$ & $172,0^{C}$ \\
\hline
\end{tabular}

${ }^{1)}$ Valores seguidos de letras iguais dentro da coluna não diferem pelo teste Tukey a $5 \%$. 
condições ambientais normais, os citros são submetidos a um certo grau de estresse hídrico, no período da tarde,

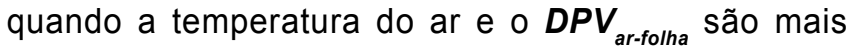
elevados, mesmo em condições de umidade do solo na capacidade de campo. Em outras espécies como arroz, milho e trigo não se observaram queda da fotossíntese e da condutância no período da tarde (Machado \& Lagôa, 1994).

O potencial da água na folha apresentou o mesmo padrão de resposta nos meses estudados, sendo alto pela manhã e decrescendo significativamente à tarde. No entanto, os valores de $\Psi_{f}$ foram relativamente maiores em julho (Figura 6). O padrão de resposta da fotossíntese durante o dia poderia estar relacionada à queda do potencial, visto que há uma relação de proporcionalidade entre $\Psi_{f}$ e $\boldsymbol{A}$ em citros (Syvertsen \& Lhoyde, 1994; Medina et al., 1998, 1999; Machado et al., 1999).

Taxas de fotossíntese e de transpiração, condutância estomática e potencial da água na folha em função do mês de medida

A variação das condições do ambiente nos meses de medidas causaram variações significativas nas taxas de fotossíntese e transpiração e na condutância estomática (Figuras 1 e 2). As taxas de fotossíntese e transpiração e a condutância estomática diminuiram significativamente no sentido dos meses mais quentes e úmidos para os mais secos e frios. Como as medidas de trocas gasosas foram feitas em folhas com aproximadamente mesmas idades, considerando apenas aquelas registradas com FFF de saturação, e a umidade do substrato de crescimento foi mantida em condições ideais, as variações observadas devem estar relacionadas com as variações climáticas e/ou com o estádio fisiológico das plantas.

Comparando-se janeiro e março, a taxa de fotossíntese e a condutância estomática foram significativamente maiores em janeiro, apesar das condições ambientais nos dias das medidas terem sido similares (Figuras 1 e 2). O DPV ar o o $D P V_{\text {ar-folha }}$ também apresentaram diferenças diminutas que dificilmente devem ter causado as variações observadas nas trocas gasosas em janeiro e março.

Por outro lado pode ter ocorrido efeito da fase de crescimento da planta sobre a fotossíntese, com a variação na demanda por fotossintetizados nos drenos. O crescimento e brotação de novos ramos eram mais vigorosos (maior demanda dos drenos) em janeiro que em março e no mês de julho a planta permaneceu praticamente em repouso vegetativo. A relação da atividade fonte/dreno afeta a fotossíntese (Lenz et al., 1972). Syvertsen (1994) observou, em plântulas de citros, que o crescimento mais ativo causou aumento na taxa de fotossíntese e na condutância estomática.

O potencial da água na folha também parece não ter sido responsável pela queda da fotossíntese no sentido de janeiro para julho, visto que esta variável

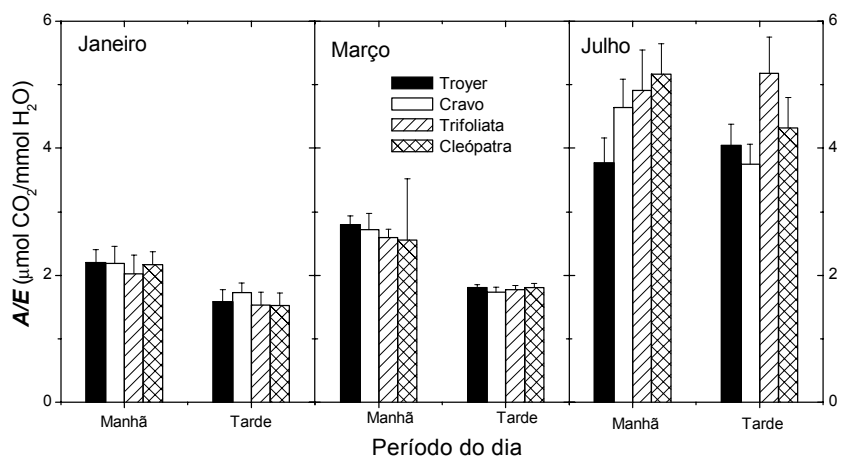

Figura 4 - Variação da eficiência do uso de água $(A / E)$ em função do período do dia e do mês de medida em laranjeira 'Valência' sobre quatro espécies de porta-enxerto. Barras indicam desvio padrão da média. Campinas, 1998.

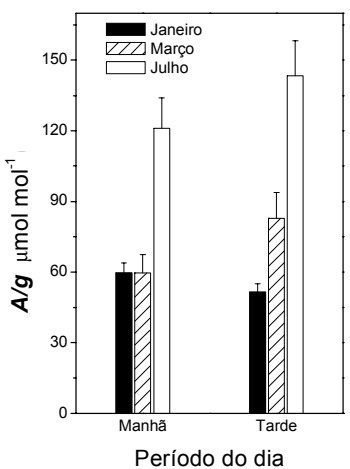

Figura 5 - Variação da eficiência intrínseca do uso de água $(A / g)$ em função do período do dia e do mês de medida em laranjeira 'Valência' sobre quatro espécies de portaenxerto. Barras indicam desvio padrão da média. Campinas, 1998.

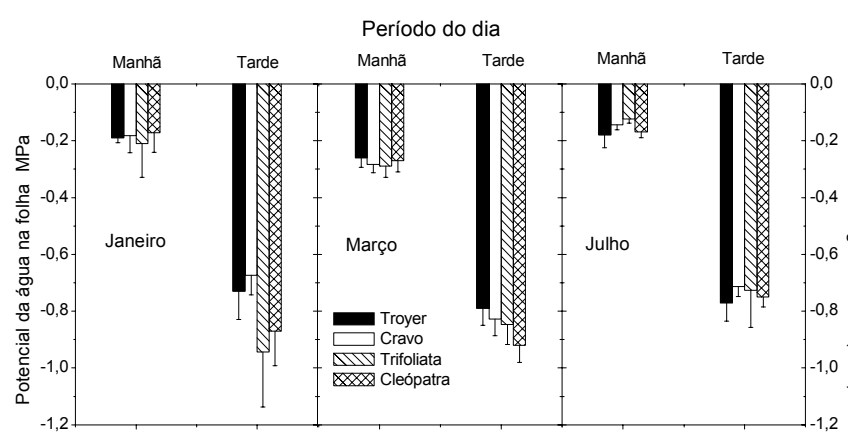

Figura 6 - Variação do potencial de água na folha em função do período do dia e do mês de medida em laranjeira 'Valência' sobre quatro espécies de porta-enxerto. Barras indicam desvio padrão da média. Campinas, 1998.

apresentou valores mais altos em julho, período de menores taxas de fotossíntese. A variação das condições de temperatura, umidade do ar e de radiação solar influenciaram o estado da água na folha, mas com magnitude aparentemente insuficiente para afetarem também a taxa de fotossíntese. 
A temperatura do ar diurna $\left(20^{\circ} \mathrm{C}\right.$ a $\left.26^{\circ} \mathrm{C}\right)$ próxima à faixa considerada ideal para os citros $\left(22^{\circ} \mathrm{C}\right.$ a $25^{\circ} \mathrm{C}$ ) (Kriedmann, 1971; Khairi \& Hall, 1976), não pode ter contribuído para a redução da taxa de fotossíntese. Mas, a temperatura noturna em julho variou entre $19^{\circ} \mathrm{C}$ e $13^{\circ} \mathrm{C}$, enquanto que em janeiro e março variou entre $26^{\circ} \mathrm{C}$ e $20^{\circ} \mathrm{C}$. Durante o mês de julho foram observadas várias noites e também dias com temperaturas ainda menores (dados não mostrados). Talvez a alta freqüência de temperaturas baixas em julho tenha afetado a fotossíntese e a condutância estomática, diminuindo-as significativamente. No entanto, não encontramos relatos sobre o efeito da temperatura noturna sobre a fotossíntese em citros.

A relação $\boldsymbol{A} / \boldsymbol{g}$ foi progressivamente maior no sentido de janeiro para julho, indicando que a redução da taxa de fotossíntese foi relativamente menor que aquela da abertura estomática (Figura 5). 0 mesmo também ocorreu para a razão $\boldsymbol{A} / \boldsymbol{E}$, indicando que o fechamento parcial dos estômatos afetou mais a transpiração que a fotossíntese (Figura 4).

Considerando-se o aspecto dinâmico tanto das condições ambientais como do crescimento e desenvolvimento das plantas nos diferentes meses do ano, as variações observadas nas trocas gasosas devem estar relacionadas simultaneamente com a variação dos fatores climáticos e com os fisiológicos. As diferenças entre janeiro e março, parecem estar mais relacionadas com o efeito de maior demanda de fotossintetizados para manutenção de brotação intensa em janeiro, que consequentemente afetaria a taxa de fotossíntese. Já em relação ao mês de julho, a baixa fotossíntese parece estar relacionada ao aparente repouso do crescimento vegetativo e à baixa temperatura noturna.

\section{AGRADECIMENTO}

À Fundação de Amparo a Pesquisa do Estado de São Paulo - FAPESP, pelo financiamento desta pesquisa.

\section{REFERÊNCIAS BIBLIOGRÁFICAS}

BRAKKE, M.; ALLEN JR., L.H. Gas exchange of Citrus seedlings at different temperatures, vapor-pressure deficits, and soil water content. Journal of the American Society for Horticultural Science, v.120, p.497-504, 1995.

EAMUS, D.; COLE, S. Diurnal and seasonal comparisons of assimilation, phyllode conductance and water potential of three Acacia and one Eucalyptus species in the wet-dry tropics of Australia. Australian Journal of Botany, v.45, p.275-290, 1997.

FIGUEIREDO, J.O. Variedades comerciais. In: RODRIGUEZ, O.; VIÉGAS, F.; POMPEU JR., J.; AMARO, A.A. (Ed.) Citricultura brasileira. 2.ed. Campinas: Fundação Cargill, 1991. v.1, p.228-264.
HABERMANN, G. Trocas gasosas e relações hídricas em laranjeiras-doce (Citrus sinensis L. Osbeck cv. Pera) com clorose variegada dos citros (CVC). Botucatu, 1999. 79p. Dissertação (Mestrado) - Universidade Estadual Paulista "Júlio de Mesquita Filho".

HALL, A.E.; CAMACHO, B.S.E.; KAUFMANN, M.R. Regulation of water loss by citrus leaves. Physiologia Plantarum, v.33, p.62-65, 1975.

KAUFMANN, M. Evaluation of the pressure chamber method for measumement of water stress in citrus. Proceedings of the American Society for Horticultural Science, v.93, p.186198, 1968.

KHAIRI, M.M.A.; HALL, A.E. Temperature and humidity effects on net photosynthesis and transpiration of citrus. Physiologia Plantarum, v.36, p.29-34, 1976.

KITAO, M.; LEI, T.T.; KOIKE, T.; TOBITA, H.; MARUYAMA, Y.; MATSUMOTO, Y.; ANG, L.H. Temperature response and photoinhibition investegated by chlorophyll fluorescence measurements of four distinct species of dipterocarp trees. Physiologia Plantarum, v.109, p.284-290, 2000.

KRIEDMANN, P.E. Photosynthesis and transpiration as function of gaseous diffusive resistance in orange leaves. Physiologia Plantarum, v.24, p.218-225,1971.

LENZ, F.; KRIEDMANN, P.E.; DAUNICHT, H.J. Effects of roots and emerging auxiliary shoots on photosynthetic behaviour of citrus cutting. Angewandte Botanik, v.46, p.227-231, 1972.

MACHADO, E.C.; LAGÔA, A.M.M.A. Trocas gasosas e condutância estomática em três espécies de gramíneas. Bragantia, v.53, p.141-149, 1994

MACHADO, E.C.; QUAGGIO, J.A.; LAGÔA, A.M.M.A.; TICELLI, M.; FURLANI, P.R. Trocas gasosas e relações hídricas em laranjeiras com clorose variegada dos citros. Revista Brasileira de Fisiologia Vegetal, v.6, p.53-57, 1994.

MACHADO, E.C.; MEDINA, C.L.; GOMES, M.M.A. Teor de água no substrato de crescimento e fotossíntese em laranjeira 'Valência'. Bragantia, v.58, p.217-226, 1999.

MEDINA, C.L.; MACHADO, E.C.; PINTO, J.M. Fotossíntese de laranjeira 'Valência' enxertada sobre quatro porta-enxertos e submetida à deficiência hídrica. Bragantia, v.57, p.1-14, 1998.

MEDINA, C.L.; MACHADO, E.C.; GOMES, M.M.A. Condutância estomática, transpiração e fotossíntese em laranjeira 'Valência' sob deficiência hídrica. Revista Brasileira de Fisiologia Vegetal, v.11, p.29-34, 1999.

POMPEU JR., J. Porta-enxertos. In: RODRIGUEZ, O.; VIÉGAS, F., POMPEU JR., J.; AMARO, A.A. (Ed.) Citricultura brasileira. 2.ed. Campinas: Fundação Cargill, 1991. v.1, p.265-280.

PRIOR L.D.; EAMUS, D.; DUFF, G.A. Seasonal and diurnal patterns of carbon assimilation, stomatal conductance and leaf water potential in Eucalyptus tetrodonta sampling in a wet-dry savanna in northern Australia. Australian Journal of Botany, v.45, p.241-258, 1997.

SYVERTSEN, J.P. Partial shoot removal increases net $\mathrm{CO}_{2}$ assimilation and alters water relations of citrus seedlings. Tree, v.14, p.497-508, 1994.

SYVERTSEN, J.P.; LLOYD, J.J. Citrus. In: SCHAFFER, B.; ANDERSEN (Ed.) Handbook of environmental physiology of fruits crops. Boca Raton: CRC Press, 1994. v.2, p.6599.

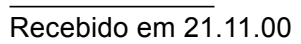

